Revue

Revue de l'histoire des religions

de Ihistoire des religions

$2 \mid 2006$

Varia

\title{
Philippe Martin, Une religion des livres (1640-1850)
}

Éditions du Cerf, Paris, 2003

\section{François Laplanche}

\section{(2) OpenEdition}

Journals

Édition électronique

URL : http://journals.openedition.org/rhr/5148

DOI : 10.4000/rhr.5148

ISSN : 2105-2573

Éditeur

Armand Colin

Édition imprimée

Date de publication : 1 juin 2006

Pagination : 237-239

ISBN : 2200-92104-7

ISSN : 0035-1423

Référence électronique

François Laplanche, "Philippe Martin, Une religion des livres (1640-1850) », Revue de l'histoire des religions [En ligne], 2 | 2006, mis en ligne le 20 janvier 2010, consulté le 22 septembre 2020. URL : http://journals.openedition.org/rhr/5148; DOl : https://doi.org/10.4000/rhr.5148

Ce document a été généré automatiquement le 22 septembre 2020

Tous droits réservés 


\title{
Philippe Martin, Une religion des livres (1640-1850)
}

\author{
Éditions du Cerf, Paris, 2003
}

\section{François Laplanche}

\section{RÉFÉRENCE}

Philippe Martin, Une religion des livres (1640-1850), les Éditions du Cerf, Paris, 2003, $23 \mathrm{~cm}$, 622 p., (« Histoire religieuse de la France », 22), $49 €$.

1 Ce livre imposant, publié avec le concours de l'Université de Nancy-II et du ministère de la Culture, vient combler une évidente lacune. Car les formes de la transmission des croyances catholiques ont plutôt été étudiées à travers des institutions orientées vers la collectivité des fidèles : les pèlerinages, les catéchismes, la liturgie et la prédication. De son enquête personnelle, l'auteur tire la thèse centrale que la lecture du livre de dévotion permet l'appropriation des croyances catholiques par l'individu. De ce fait, elle participe, en même temps qu'elle contribue, à la formation de l'individualisme des Temps modernes.

2 Pour manier son enquête de manière significative, l'auteur, professeur d'histoire moderne à l'Université de Nancy, a dressé une comparaison entre deux corpus régionaux, inventoriés par lui dans les bibliothèques lorraines et dans celles de Savoie (essentiellement les bibliothèques diocésaines de Nancy et de Saint-Dié, celles d'Annecy et de Chambéry, auxquelles est joint l'important fonds de livres religieux de la Bibliothèque municipale de Chambéry). Philippe Martin a mené l'étude de 2230 éditions différentes et il présente les résultats obtenus en trois étapes intitulées: «L'objet ", "L'intention des auteurs ", «La pratique ». La première étape s'attache à décrire la naissance du livre de dévotion au XVII ${ }^{\mathrm{e}}$ siècle, l'apparition de l'auteur, sorti de l'anonymat des époques précédentes, et les circuits commerciaux du livre pieux. La seconde étape étudie la reproduction du système des croyances à travers le livre : quels sont les thèmes dominants, connaissent-ils des variations significatives ? La troisième 
étape se soucie des pratiques de lecture : sont-elles encadrées, par qui et comment? Comment faut-il lire ? Jusqu'à quel point la pratique de la lecture pieuse devient-elle un exercice qui porte la marque de l'individualité du lecteur?

Comme cette littérature est très répétitive, la première impression qu'elle donne est celle d'un paysage gris. En effet, les auteurs se recopient les uns les autres, les rééditions se multiplient et les ouvrages du XVII e siècle sont réimprimés avec succès encore au XIX ${ }^{e}$ siècle. Cette monotonie s'affirme dans la constance des thèmes développés, dont l'uniformité largement répandue occulte, selon l'auteur, la diversité des écoles théologiques qui se sont affrontées dans le catholicisme français : jansénistes et jésuites, quiétistes et adeptes de l'ascèse méthodique, rigoristes et indulgents. Le thème du salut individuel, ultime mais unique but de l'existence personnelle, est omniprésent, et il s'agit pour l'obtenir de vivre par et pour Dieu, dans un effort renouvelé de vie en sa présence et d'éloignement du péché. Nous ne sommes pas loin de la "pastorale de la peur", chère à Jean Delumeau, compensée par le rôle des intercesseurs, au sein desquels la Vierge Marie joue un rôle éminent. Les premiers chapitres du livre se meuvent dans cette atmosphère de grisaille, que n'éclairent pas beaucoup les touches de lumière venues des infinies nuances entre ces expressions du sentiment religieux à l'époque moderne et l'importance donnée à la vocation personnelle, sous la forme du « devoir d'état».

4 L'auteur n'a pas cherché à corriger la monotonie de l'information quantitative par la mise en vedette de quelques textes mieux venus, par l'originalité de leur contenu ou la qualité de leur écriture. Tout au contraire, il a su donner vie à son corpus apparemment immobile par l'emploi de la méthode la mieux adaptée à l'objet étudié : la méthode statistique. Elle a nécessité la constitution d'une fiche type, destinée au tri des thèmes traités par la littérature de dévotion et le traitement informatique de ces fiches grâce à un logiciel de statistiques. Ces investigations ont permis à l'auteur de périodiser la production étudiée : il nous conduit de la littérature pour dévots (1640-1698) à l'effort qui accompagne le progrès de l'alphabétisation dans la France du Nord et de l'Est (1699-1771) pour jeter les racines personnelles d'une foi éclairée; puis la secousse révolutionnaire et ses effets déchristianisateurs obligent à une entreprise systématique de formation des fidèles (1771-1819). Enfin le second quart du XIX siècle voit s'épanouir le besoin de modèles et d'intercesseurs, dans le climat de reconstruction catholique (1820-1850). Par ailleurs, la périodisation apparait plus nettement dans la troisième partie : s'agissant des pratiques de lecture, la situation ne peut être la même, quand le livre de dévotion est lu par une élite de laïcs épris de perfection, quand il est vendu sur les marchés par les "épiciers libraires », et quand la «lecture spirituelle » devient l'obligation de tout chrétien pieux.

5 Ce grand travail ne pourra pas être ignoré des historiens de la religion des Français à l'époque moderne. Il corrige fortement le tableau en noir et blanc, selon lequel le catholicisme se serait adressé à des paysans analphabètes par le moyen de cérémonies collectives, aux symboles voyants. L'auteur enfonce au contraire ce clou: le développement imposant de l'édition catholique, $\mathrm{du}_{\mathrm{XVII}}{ }^{\mathrm{e}}$ au $\mathrm{xIX}^{\mathrm{e}}$ siècle, marque une profonde individualisation de la croyance catholique. Cette conclusion appelle une question : cette individualisation n'a-t-elle pas eu pour effet la courbure de la foi sur le moi, sur « mon âme qu'il faut sauver »?

6 En effet, le type de piété intériorisée transmis par le livre de dévotion sur deux siècles porte visiblement la trace de la dévotion du xviI ${ }^{\mathrm{e}}$ siècle. Ne véhicule-t-il pas une sorte 
de dualisme, un attrait pour le "retrait du monde ", même si chacun doit faire à la société qui l'entoure les concessions nécessaires à son état (comme le rappelle l'auteur au chapitre VII) ? Du moins, ce christianisme acquis à l'intériorité semble assez peu tourné vers l'engagement dans les tâches du monde, réclamé par les bouleversements politiques, religieux et sociaux du début du $\mathrm{xIX}^{\mathrm{e}}$ siècle. Et l'on est un peu surpris que l'enquête de Philippe Martin ne semble pas avoir rencontré le romantisme catholique, déclencheur d'initiatives culturelles, caritatives et politiques. Certes, cette école, qui prélude de loin à l'action catholique, n'a peut-être pas laissé de traces dans la littérature de dévotion explorée par l'auteur de La religion des livres. On est étonné par exemple que le livre de Philippe Gerbet, compagnon de Lamennais puis évêque de Perpignan, Considérations sur l'Eucharistie, dogme générateur de la piété catholique, édité une vingtaine de fois au XIX siècle, ne soit pas mentionné. C'est évidemment parce que l'auteur ne l'a pas trouvé dans les fonds explorés par lui. Mais on doit constater alors une sorte de fossé entre la piété des masses catholiques et les interrogations de l'intelligence catholique au début du XIX siècle sur le rôle de l'Église dans un monde nouveau. Le livre de Philippe Martin appelle donc un chapitre supplémentaire, qui explorerait la place de l'Église dans le livre de dévotion. On n'oubliera pas qu'en son temps, le volume de Henri de Lubac, Catholicisme. Aspects sociaux du dogme, fut salué comme une grande nouveauté. L'individualisation de la piété, amplement démontrée par l'extension de la «religion des livres» ne fut-elle pas la promotion de la piété individuelle, la lecture étant par excellence l'acte qui isole l'individu du groupe? L'élargissement de la question inscrit finalement l'enquête de Philippe Martin dans une histoire générale de la culture à l'âge moderne.

\section{AUTEURS}

\section{FRANÇOIS LAPLANCHE}

Centre national de la Recherche scientifique 